\title{
ÉVOLUTION DE LA SÉCRÉTION DES MATIÈRES GRASSES, DES MATIÈRES AZOTÉES ET DU LACTOSE AU COURS DU PREMIER MOIS DE LACTATION
}

\author{
PAR \\ M. JOURNET et R. JARRIGE

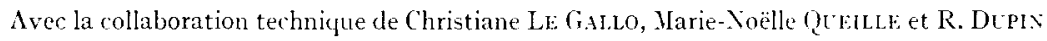 \\ Station de Recherches sur l'Elevage, C. I. R. Z., Jouy-en-Josas. (S.-et-O.).
}

\section{SOMMAIRE}

Au cours du premier mois de lactation de 43 vaches : a) la quantité de lait et la teneur en lactose ont augmenté suivant une loi hyperbolique, $b$ ) la teneur en matières azotées totales a diminué suivant une loi logarithmique, c) la teneur en matières grasses a diminué de façon moins régulière. Les productions journalières maximum ont été réalisées, a) les premier et deuxième jours pour la quantité de matières azotées totales, $b$ ) les neuvième et dixième jours pour les quantités de matières grasses, de caséine et de calories, c) les vingt-cinq et vingtsixième jours pour les quantités de lait et de lactose. La composition de la matière organique a évolué de façon très régulière; la proportion de lactose a augmenté au détriment de la proportion de matières grasses et surtout de la proportion de matières azotées.

La phase ascendante de la lactation est beancoup plus mal connue que la phase décroissante qui a pu être étudiée à partir des résultats du Contrôle laitier ( $C f$. Delagk, Legroy et Poly, I953). Pourtant elle revêt une importance capitale dans le déroulement de la lactation et pose de nombreux problèmes physiologiques et nutritionnels. Nous rapportons ici les premiers résultats d'une étude poursuivie dans un double but:

- Préciser l'évolution de la teneur et de la production des principaux constituants du lait et en donner, si possible, une expression mathématique ;

- En déduire l'évolution des besoins énergétiques et azotés de la vache laitière après le vêlage. 


\section{MATÉRIEL E'T MÉTHODES.}

\section{Animaux.}

Nous avons étudié 43 lactations fournies par les vaches du C. N. R. Z. dont le tableau I donne la répartition par race, numéro de lactation, date de vêlage et niveau de production : la production maximum de ces animaux a varié de ro $\mathrm{kg}$ à $37 \mathrm{~kg}$ de lait, avec une moyenne de $19,3 \mathrm{~kg}$.

Toutes ces vaches ont eu un vêlage normal et n'ont pas présenté de mammite ou de troubles digestifs au cours de la période. Elles ont eu une alimentation adaptée chaque semaine à leurs besoins, à base de foins, d'ensilages et de betteraves pendant l'hiver (début novembre à mi-avril) et d'herbe pendant l'été. Elles ont toutes vêlé en bon état, d'autant plus qu'en hiver elles ont reçu, au cours des cinq dernières semaines semaines de gestation, une petite quantité d'aliments concentrés, proportionnellement à la production attendue. Nous pensons avoir ainsi réduit au minimum l'influence des facteurs alimentaires et enregistré au mieux l'évolution physiologique de la production et de la composition du lait.

\section{Prélèvements et analyses.}

A partir des prélèvements effectués à chaque traite, nous avons constitué des échantillons pondérés sur 48 heures et analysé ainsi I5 échantillons successifs pour chaque vache du ${ }^{\mathrm{er}}-2^{\mathrm{e}}$ jour au $29^{\mathrm{e}}-3 \mathrm{o}^{\mathrm{e}}$ jour. En réalité, il s'agit moins de jours que de traites; le premier échantillon correspond en effet aux 4 ou 6 premières traites après le vêlage, selon que la vache a été traite deux fois par jour ou trois fois (en principe les vaches donnant plus de $20 \mathrm{~kg}$. par jour à la fin du prenier mois).

Sur ces échantillons, conservés au toluène, nous avons dosé les matières grasses par la méthode de GIRBER, les matières azotées totales

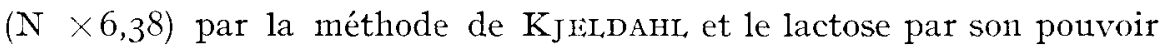
réducteur déterminé suivant la méthode iodonetrique de Somogyi (I952) après défécation par le mélange ferrocyanure de potassium et acétate de zinc. De plus, l'azote " caséine " a été déterminé par différence entre l'azote total et l'azote du filtrat acéto-acétique (RowLAND I938) sur les 5 premiers échantillons et, ensuite, sur un échantillon par semaine.

\section{Méthodes de calcul.}

Nous avons d'abord établi 1'évolution moyenne des teneurs et des productions pour l'ensemble des 43 animaux. Nous en avons cherché l'expression mathématique dans un certain nombre de cas en utilisant 
(9, I960) SF́CRÉTION AU PREMIER MOIS DE LACTATION

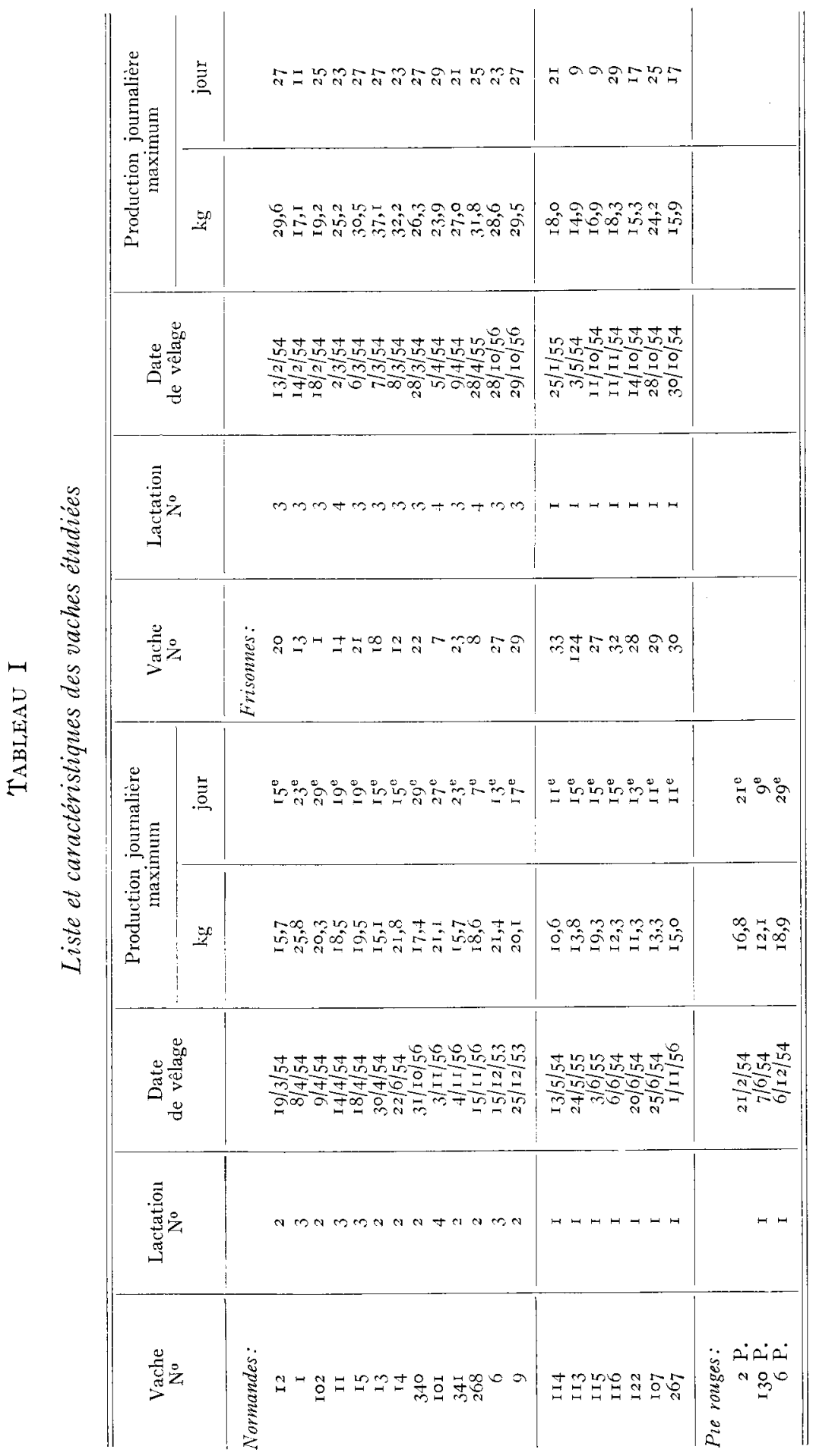


la méthode exposée par Delage, Leroy et Poly (1953) (1). Ia valeur statistique de l'ajustement a été testée en rapportant la variance des déviations par rapport à la régression, à la variance des valeurs individuelles à l'intérieur de chaque classe.

Pour étudier ensuite l'influence des différents facteurs nous avons réparti les animaux :

- par race : deux groupes de 20 animaux pour les races normandes et frisonnes.

- par $n^{\circ}$ de lactation:

- I groupe de I6 premières lactations,

- I groupe de 27 lactations ultérieures.

- par date de vêlage:

- II animaux ont vêlé en automne (octobre, novembre, décembre);

- I7 en hiver (janvier, février, mars);

- I5 au printemps (avril, mai, juin).

- par niveau de production maximum.

$\begin{array}{lll}\text { Groupe I : } & <\text { I5 kg } & \text { I3 animatux } \\ \text { Groupe II : } & \text { I5-20 kg } & \text { I3 animaux } \\ \text { Groupe III : } & 20-25 \mathrm{~kg} & 9 \text { animaux } \\ \text { Groupe IV : } & >25 \mathrm{~kg} & 8 \text { animaux }\end{array}$

RÉSULTATS.

Quantité de lait.

La production moyenne de nos 43 animaux a augmenté rapidement au cours des deux premières semaines (tableau II, graphique I), plus lentement ensuite et atteint son maximum au cours de la quatrième semaine (25-26e jour). En p. Ioo de cette production maximum, elle a été successi-

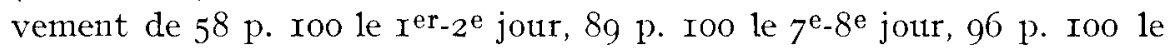
$\mathrm{I} 3^{\mathrm{e}}-\mathrm{I} 4^{\mathrm{e}}$ jour et $99,5 \mathrm{p}$. roo le $2 \mathrm{I}^{\mathrm{e}}-22^{\mathrm{e}}$ jour. Elle a diminué régulièrement dès la fin du premier mois de lactation et a été à $86 \mathrm{p}$. Ioo du maximum à la fin du deuxième mois.

Nous avons ajusté la courbe moyenne entre le $3^{\mathrm{e}}-4^{\mathrm{e}}$ et le $29^{\mathrm{e}}$ $3^{\mathrm{e}}$ jour à une hyperbole de la forme :

$$
\begin{aligned}
& y=\frac{a}{x}+b, \\
& a=-\mathrm{I} 6,66, \\
& b=+19,83 .
\end{aligned}
$$

(1) Nous sommes reconnaissants à Monsieur J. POLY de nous avoir guidés dans liAnalyse statistique des résultats. 
Cet ajustement est très satisfaisant : la variance des déviations par rapport à la régression est inférieure à la variance intraclasse ; l'écart maximum entre 1'hyperbole et la courbe réelle ne dépasse pas $0,5 \mathrm{~kg}$; il faut noter cependant que l'hyperbole se situe légèrement au-dessus de la courbe réelle du $5^{\mathrm{e}}$ au $\mathrm{I}^{\mathrm{e}}$ jour et au-dessous, $d u{ }^{\mathrm{e}}$ au $25^{\mathrm{e}}$ jour (graph.I).

\section{TABLEAU II}

Évolution de la quantité et de la composition du lait (moyenne des 43 animaux).

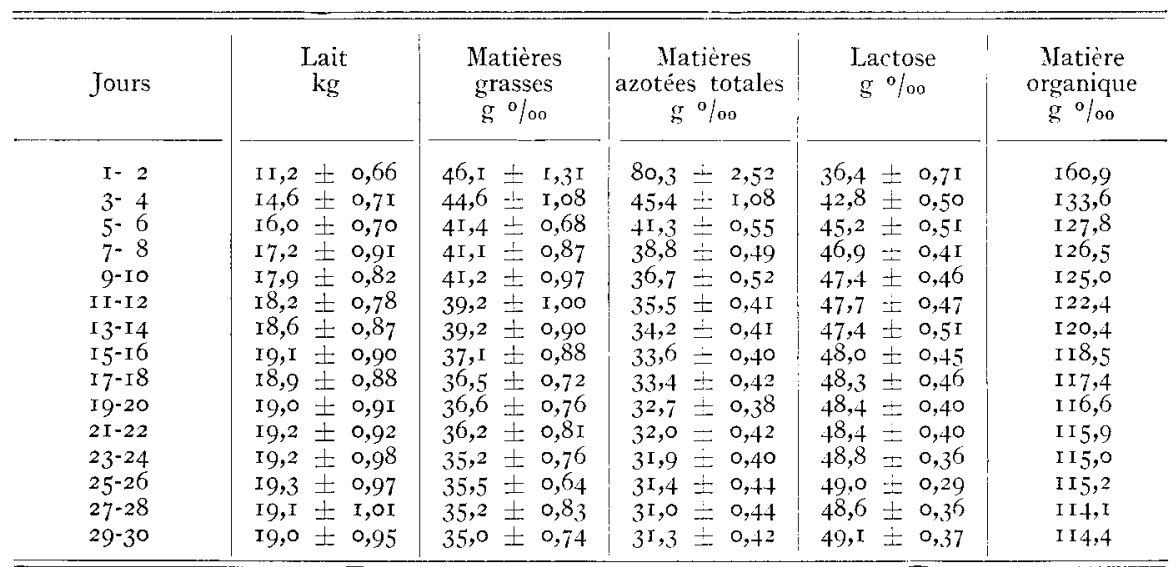

Nous retrouvons cette évolution caractéristique chez toutes les vaches avec des variations dans sa vitesse et dans la position du maximum par rapport au vêlage.

En moyenne plus la production maximum est élevée, plus tard elle est atteinte, comme le montrent le graphique. 5 et le tableau suivant :
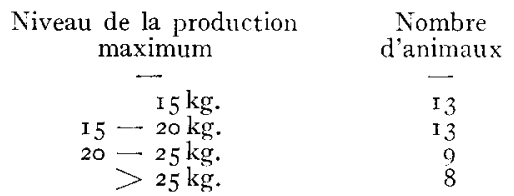

$$
\begin{aligned}
& \text { Position du } \\
& \text { maximum } \\
& \text { - } \\
& 9 \text {-ro'me jour } \\
& 19-20^{\text {ème jour }} \\
& 27-28^{\text {ème jour }} \\
& 23-24^{\text {ème jour }}
\end{aligned}
$$

Ce fait classique (TURNER et al., I923) explique en majeure partie les différences que nous observons entre les races, les lactations successives et les saisons de vêlage. Ainsi, les Normandes ont réalisé leur production maximum $(\mathrm{I} 6,5 \mathrm{~kg}) 1 \mathrm{e} \mathrm{I}^{\mathrm{e}}$ jour, ro jours plus tôt que les Frisonnes $\left(22,9 \mathrm{~kg} 1 \mathrm{e} 25^{\mathrm{e}}\right.$ jour $)$. De même la courbe moyenne des premières lactations a différé sensiblement de celle des lactations ultérieures; elle a atteint son maximum huit jours plus tôt ( $5^{\mathrm{e}}$ jour au lieu du $23^{\mathrm{e}}$ ) et s'y est maintenue plus longtemps ( 5 jours au lieu de 5 ) ; elle a diminué 
relativement moins vite au cours du detxième mois : à la $8^{\mathrm{e}}$ semaine 89 p. Ioo du maximum pour les premières lactations contre 85 p. Ioo pour les lactations ultérieures. En définitive, les premières lactations présentent un palier maximum et les lactations ultérieures une véritable pointe maximum, qui a peut-être été accentuée par l'apport de concentrés avant le vêlage. Dans une publication ultérieure, nous nous proposons d'analyser ces facteurs sur un plus grand nombre de données.

\section{Teneur en lactose.}

Pour l'ensemble des 43 lactations (tableau II) la teneur en lactose a augmenté durant tout le premier mois (maximum : 49, I $\pm 0,37 \mathrm{~g}$ p. Iooles $29-30^{\mathrm{e}}$ jours) suivant une courbe grossièrement semblable à celle de la quantité de lait (graph. I). La majeure partie de cette augmentation a été réalisée dans la première semaine $\left(36,4 \pm 0,7 \mathrm{I}\right.$ le $\mathrm{I}^{\mathrm{er}} 2^{\mathrm{e}}$ jour, $42,8 \pm 0,50$ le $3^{\mathbf{e}_{-}}{ }^{\mathbf{e}}$ jour, $46,9 \pm 0,4 \mathrm{I}$ le $7^{\mathrm{e}_{-}} \mathbf{e}^{\mathrm{e}}$ jour). La dispersion des valeurs individuelles autour de la moyenne diminue de façon assez régulière : elle est maximum pour les laits colostraux : $\mathrm{m}=0,7 \mathrm{I}$ et minimum le $25-26$ e jour : $m=0,24$.

Nous avons ajusté cette courbe moyenne à une hyperbole en ne tenant pas compte de la valeur du $\mathrm{I}^{\mathrm{er}}{ }_{-2}{ }^{\mathrm{e}}$ jour :

$$
\begin{aligned}
& y=\frac{a}{x}+b, \\
& a=-20,35, \\
& b=49,5 \mathrm{I},
\end{aligned}
$$

Cet ajustement, valable au seuil 5\% est moins étroit que celui de la quantité de lait (valable au seuil I\%, comme le montre bien la comparaison des courbes du graphiques I).

Les courbes individuelles sont très semblables à cette courbe moyenne mais présentent quelques différences systématiques en fonction du numéro de la lactation et du niveau de production. Chez les génisses, la teneur en lactose est toujours significativement plus élevée que chez les vaches, en général de 2 à 3 points; d'autre part, les valeurs individuelles sont plus groupées : pour chaque prélèvement l'erreur type est environ deux fois plus faible. Enfin, si la teneur en lactose n'atteint son maximum $\left(5^{0}, 5 \mathrm{~g}\right.$ p. I ooo) que le $29-30^{\mathrm{e}}$ jour, elle l'approche dès le I5-I6 ${ }^{\mathrm{e}}$ jour (49,9 g p. I ooo); au contraire, elle augmente, pendant cette période chez les vaches et passe de 47,0 à 48,4 entre le $I_{5}-\mathrm{I} 6^{\mathrm{e}}$ et $1 \mathrm{e} 25-26^{\mathrm{e}}$ jour.

Nous retrouvons la même différence entre les Normandes et les Frisonnes : la teneur en lactose présente un palier maximum chez les premières à partir $\mathrm{du} \mathrm{I} 7^{\mathrm{e}}$ jour, alors qu'elle continue à augmenter chez les Frisonnes jusqu'au 25-26e jour. Ainsi, dans les deux comparaisons, 
GRAPIIIQUE I.

Evolution de la quantité de lait et de la teneur en lactose au cours du premier mois de lactation (moyenne des 43 animaux).

\section{Courbe observée}

- - - - Ajustement hyperbolique

\section{Graphiole 2.}

Fvolution des teneurs en matières grasses et en matières azotées totales au cours du premier mois de lactation (moyeme des 43 animaux).

\section{Courbe observée}

Ajustement logarithmique
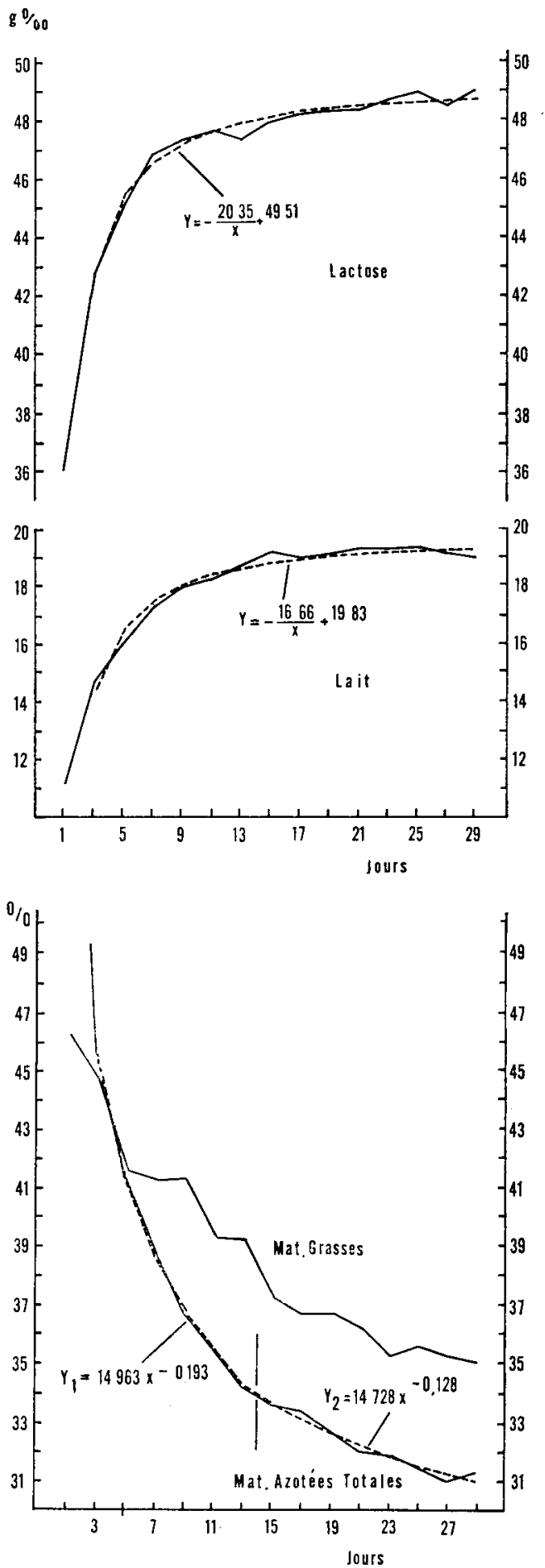
génisses et vaches d'une part, Normandes et Frisonnes d'autre part, la quantité de lait et la teneur en lactose ont eu une évolution identique au cours des $3^{\mathrm{e}}-4^{\mathrm{e}}$ semaines de lactation. Nous retrouvons la même similitude lorsque nous classons les lactations par niveau de production (graph.5) ou par saison de vêlage.

\section{Teneur en matières grasses.}

Très élevé dans les laits colostraux (46, I g p. I ooo \pm I,3) le taux butyreux moyen des 43 animaux (tableau II) a diminué rapidement au cours. des deux premières semaines, plus lentement ensuite et a présenté des valeurs sensiblement constantes du $23-24^{\mathrm{e}}$ au $29-30^{\mathrm{e}}$ jour $(35,2 \mathrm{~g}$ p. I ooo). Cette évolution moyenne (graph. 2) n'a pas été aussi régulière que celle des. teneurs en lactose et en matières azotées, par suite des fluctuations journalières entraînant une plus grande dispersion des valeurs individuelles. Celle-ci a été particulièrement élevée pour les deux premiers prélèvements; les valeurs de l'erreur type ont été respectivement de I,3I et I,08, car certaines vaches normandes ont eu des laits colostraux très pauvres. en matières grasses. Elle a ensuite diminué jusqu'au $5^{\text {e-6 }}$ e jour, aussi bien chez les vaches que chez les génisses et remonté sensiblement pour diminuer à nouveau et présenter des valeurs de 0,7 à 0,8 du I7-I $8^{\mathrm{e}}$ au $29^{-}$ $30^{\mathrm{e}}$ jour. En raison de cette dispersion, il faudrait un nombre d'animaux beaucoup plus important pour pouvoir définir mathématiquement cette évolution.

Le taux butyreux des génisses a été systématiquement plus élevé que celui des vaches, la différence étant en moyenne de deux points mais allant en s'amenuisant. Il a diminué de façon plus rapide $(0,35 \mathrm{~g}$ p. I ooo par jour en moyenne, contre $0,29 \mathrm{p}$. I 000$)$, mais beaucoup plus irrégulière que chez les vaches; en effet, il a présenté deux phases de décroissance linéaire, du $\mathrm{I}^{\mathrm{er}} \mathrm{2}^{\mathrm{e}}$ au $5^{-6} \mathrm{e}^{\mathrm{e}}$ jour, puis du 9-IO ${ }^{\mathrm{e}}$ jour, au $\mathrm{I}$ 7-I 8 e jour séparées par une remontée qui semble systématique (graph. 7).

Malgré le nombre restreint d'animaux, il apparaît une différence importante entre les deux races. L,e taux butyreux des Frisonnes a été très élevé au vêlage $(48,9 \mathrm{~g} \pm 2,5)$ et a diminué de façon rapide et continue jusqu'à la fin du mois $(33,2 \mathrm{~g}$ pour les deux derniers prélèvements). L'amplitude de cette diminution a été approximativement double de celle des Normandes dont le taux butyreux, plus faible au vêlage $(43,3 \pm I, 0)$ a pré-

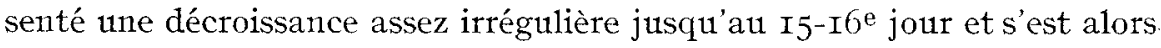
stabilisé (entre 37 et $38 \mathrm{~g}$ ) en même temps que la quantité de lait. La présence d'une majorité de Frisonnes explique en grande partie la diminution. rapide et accentuée du taux butyreux dans le groupe des vaches vêlées en. hiver, d'une part, et dans le groupe des vaches à production supérieure à. 
I5 kg, d'autre part. A noter également que le taux butyreux des frisonnes a présenté une variabilité plus faible que celui des normandes.

\section{Teneur en matières azotées.}

La teneur en matières azotées des laits colostraux a été très élevée (moyenne générale $: 80,3 \mathrm{~g} \mathrm{p}$. Iooo $\pm 2,5$ ) mais très variable $:$ de $43 \mathrm{p}$. Iooo à I2I p. Iooo. Flle est tombée à $45,4 \mathrm{~g} \pm \mathrm{I}, 08 \mathrm{le} 3-4^{\mathrm{e}}$ jour et a ensuite diminué à une vitesse décroissante jusqu'à un minimum de 3 I g le $27^{\mathrm{e}}$ jour. Cette évolution a été extrêmement régulière et les valeurs individuelles bien groupées autour de la moyenne dont l'erreur type a diminué de 0,55 le $5^{\mathrm{e}}$ jour à des valeurs sensiblement constantes de 0,40 à 0,45 à partir

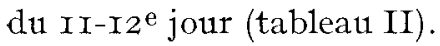

Nous avons donc cherché à ajuster cette courbe entre le $3-4^{\mathrm{e}}$ et le 29-30 jour, à différentes courbes mathématiques simples. L'ajustement à une parabole a été mauvais, celui à une hyperbole imparfait. Le meilleur s'est montré de la forme :

$$
y=a \cdot x^{b}
$$

avec les valeurs suivantes :

$$
\begin{aligned}
& a=\mathrm{I} 4,893, \\
& b=-\mathrm{o}, \mathrm{I} 68 .
\end{aligned}
$$

Cet ajustement à une droite en coordonnées logarithmiques n'est cependant pas valable au seuil 5 p. Ioo, à cause de la remontée observée le 29-30 jour. Par contre l'ajustement à la courbe :

$$
y=\mathrm{I} 4902 x^{-0,171}
$$

entre le $3-4^{\mathrm{e}}$ jour et le $27-28$ e jour est valable au seuil 5 p. roo. Cependant dans ce système de coordonnées, l'évolution de la teneur en matières azotées semble être beaucoup mieux représentée par deux droites, dont le point d'intersection se trouve le $\mathrm{I}^{3-\mathrm{I}} 4^{\mathrm{e}}$ jour (graph. 2). I eurs équations sont les suivantes :

- du $3^{\mathrm{e}}$ au $\mathrm{I}^{\mathrm{e}}$ jour : $\quad y_{1}=\mathrm{I} 4963 x^{\mathbf{0 , 1 9 3}}$,

- du I5 $5^{\mathrm{e}}$ au $29^{\mathrm{e}}$ jour : $y_{2}=\mathrm{I} 4728 x^{-0,128}$.

Ces deux ajustements sont valables, le premier au seuil I p. Ioo et le deuxième au seuil 5 p. Ioo.

Nous retrouvons cette évolution caractéristique avec rupture de pente au I $3^{-I} 4^{\mathrm{e}}$ jour pour tous les groupes d'animaux, avec seulement des décalages dans les ordonnées. Ainsi, la courbe des Normandes présente la même décroissance journalière $\left(0,45 \mathrm{~g}\right.$ par jour entre le $3-4^{\mathrm{e}}$ et le 29-30 jour) que celle des Frisonnes, mais se trouve au-dessus, en gros de 2 à $3 \mathrm{~g}$, exception faite des laits colostraux où la différence à été beaucoup plus élevée $\left(7,5 \mathrm{~g}\right.$ le $\mathrm{I}^{\mathrm{er}}-2^{\mathrm{e}}$ jour et 5,5 le $\left.3^{-} 4^{\mathrm{e}}\right)$. De même, la 
courbe des génisses est semblable à celle des vaches, mais systématiquement au-dessous, de 0,5 à I,5 g, fait assez surprenant car, à l'échelle de la lactation, les génisses ont un lait plus riche en matières azotées que celui des vaches. La courbe des génisses est sensiblement plus régulière que celle des vaches, son erreur type étant, dans l'ensemble, beaucoup plus faible (graph. 7).

TABLEAU III

Évolution de la répartition des constituants azotés.

\begin{tabular}{|c|c|c|c|}
\hline Jours de lactations & $\begin{array}{c}\text { Caséine/matières } \\
\text { azotées totales } \\
\%\end{array}$ & $\begin{array}{l}\text { Teneur } \\
\text { en caséine } \\
\mathrm{g} \% 00\end{array}$ & $\begin{array}{c}\text { Teneur en matières } \\
\text { azotées non caséiniques } \\
\mathrm{g} \% \mathbf{0}\end{array}$ \\
\hline $\mathrm{I}-2$ & 49,6 & 39,8 & 40,5 \\
\hline $3-4$ & $7^{22,4}$ & 32,9 & 12,5 \\
\hline $5-6$ & 76,2 & $3 \mathrm{I}, 4$ & 9,9 \\
\hline 7.8 & 76,7 & 29,7 & $9, \mathrm{I}$ \\
\hline 9 -го & 76,9 & 28,2 & 8,5 \\
\hline I3 $3^{-14}$ & 77,6 & 26,5 & 7,7 \\
\hline $21-22$ & 77,2 & 24,5 & 7,3 \\
\hline $29-3^{\circ}$ & 77,0 & $24, \mathrm{I}$ & 7,2 \\
\hline
\end{tabular}

La proportion de caséine dans les matières azotées totales a augmenté très rapidement (tableau III); elle a été en gros de $50 \mathrm{p}$. Ioo dans les laits colostraux des deux premiers jours mais elle a atteint dès la fin de la première semaine des valeurs comprises entre 76 et $77 \mathrm{p}$. Ioo, très voisines de la normale. De plus, elle a semblé indépendante de la quantité de lait produite.

\section{Composition de la « matière organique » du lait.}

Nous pouvons appeler matière organique, la somme : matières grasses + matières azotées + lactose, puisqu'elle représente la quasi totalité de la matière organique réelle du lait. Très élevé dans les laits colostraux $(\mathrm{I} 62,8 \pm 5,6)$ pour le $\mathrm{I}^{\mathrm{er}} \mathrm{2}^{\mathrm{e}}$ jour, le taux de matière organique tombe à I33, $8 \pm 4$, I le $3-4^{\mathrm{e}}$ jour et décroît ensuite constamment de façon plus rapide pendant la première quinzaine, plus lente ensuite, jusqu'à des valeurs minimum d'environ II5 $\mathrm{g}$ pour les deux derniers prélèvements (tableau II)

On peut admettre schématiquement que cette matière organique représente le produit réel synthétisé par les cellules sécrétrices, lequel est ensuite "dilué " dans la solution représentée par l'eau et les sels minéraux. Il est donc intéressant d'exprimer les teneurs en lactose, matières grasses et matières azotées en pourcentage de cette matière organique, ce qui permet d'éliminer l'interférence de la " dilution ». (tableau IV) 
Graphione 3.

Fvolution de la composition cle la mat ière organique au cours du premier mois de lactation (moyenne des 4,3 animaux)

Matière organique

= Matières grasses

+ Matières azotées

+ Lactose.

\section{Grapitique 4.}

Evolution des productions de lait et des différents constituants au cours du premier mois de lactation (movenne des 43 animaux exprimée en j. 100 des valeurs des deux premiers jours).
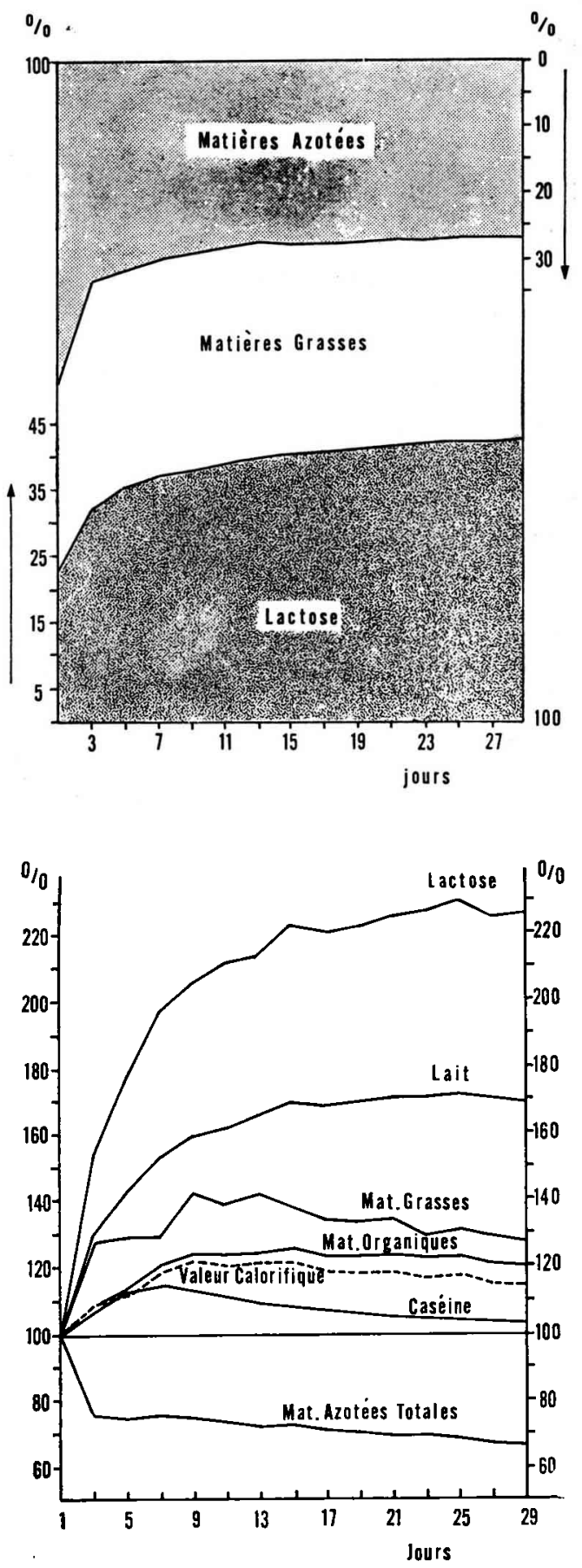
TABLEAU IV

Evolution de la composition de la matière organique du lait et des productions des différents constituants.

\begin{tabular}{|c|c|c|c|c|c|c|c|}
\hline & \multicolumn{3}{|c|}{$\begin{array}{c}\text { Composition de la matière } \\
\text { organique }\end{array}$} & \multicolumn{4}{|c|}{ Quantité produite par jour } \\
\hline & $\begin{array}{l}\text { Matières } \\
\text { grasses } \\
0\end{array}$ & $\begin{array}{c}\text { Matieres } \\
\text { azotées } \\
\%\end{array}$ & $\begin{array}{c}\text { Lactose } \\
0\end{array}$ & $\begin{array}{c}\text { Matières } \\
\text { grasses } \\
\mathrm{g}\end{array}$ & $\begin{array}{l}\text { Matières } \\
\text { azotées } \\
g\end{array}$ & $\begin{array}{l}\text { Lactose } \\
\text { ell } g\end{array}$ & $\begin{array}{c}\text { Matière } \\
\text { organique } \\
\mathrm{g}\end{array}$ \\
\hline$I-2$ & 28,5 & 48,7 & 22,6 & 515 & 878 & 409 & I 802 \\
\hline $3-4$ & $3,3,8$ & 33,8 & 32,2 & $66 \mathrm{I}$ & $66 \mathrm{I}$ & 629 & $\mathrm{I} 95 \mathrm{I}$ \\
\hline $5 \cdot 6$ & 32.5 & $3 \mathrm{I}, 9$ & 35,4 & 666 & 654 & 724 & 2045 \\
\hline $7-8$ & 32,5 & 30,3 & 37,0 & 709 & $66 \mathrm{I}$ & 807 & 2177 \\
\hline 9-10 & 32,8 & 20,3 & 37,7 & 735 & 657 & $8+5$ & 22.38 \\
\hline I I - I 2 & $3^{2}, x$ & 28,8 & 39,0 & 716 & 643 & 869 & 2227 \\
\hline $13-14$ & $3^{2}, 3$ & 27,8 & 39,8 & $73 \mathrm{I}$ & 631 & 878 & 2240 \\
\hline $15-16$ & $3 \mathrm{I}, 4$ & $28, \mathrm{I}$ & 40,4 & $7 \mathrm{II}$ & $63^{8}$ & 91 5 & 2264 \\
\hline $17-18$ & $3 \mathrm{I}, \mathrm{I}$ & 28,0 & 40,7 & 602 & 622 & 905 & 2219 \\
\hline $19-20$ & iI, & 27,7 & 41,2 & 688 & 616 & (j) 1 & 2217 \\
\hline $2 I-22$ & $i \mathrm{I}, \mathrm{I}$ & 27,2 & 41,6 & 603 & 607 & 027 & 2227 \\
\hline $23-24$ & 30,2 & 27,5 & $42, \mathrm{I}$ & 669 & 608 & 9,32 & 2209 \\
\hline $25-26$ & 30,4 & 27,0 & 42,4 & $67 i$ & 602 & 945 & 2225 \\
\hline $27-28$ & 30,5 & 26,0 & 42,4 & 666 & 588 & 92.5 & $2 I 8 I$ \\
\hline $29-30$ & 30,3 & 26,8 & $4^{2,7}$ & 659 & .584 & 930 & 2174 \\
\hline
\end{tabular}

I a matière organique des laits colostraux du $\mathrm{I}^{\mathrm{er}} \mathbf{2}^{\mathrm{e}}$ jour est caractérisée par une teneur très élevée en matières azotées $(48,7 \% \pm 2,7)$, faible en matières grasses $(28,5 \% \pm I, 6)$ et très faible en lactose $22,6 \% \pm I, 5)$. Sa composition évolue ensuite d'une façon remarquablement régulière qu'illustre le graphique 3. Ia proportion de lactose augmente continuellement, mais à une vitesse décroissante : elle passe de $32,2 \% \pm 1,7$ le $3^{\mathrm{e}}-4^{\mathrm{e}}$ jour à une valeur moyenne de 45,5 p. Ioo du $25^{\mathrm{e}}$ au $30^{\mathrm{e}}$ jour. Cette augmentation se fait en gros pour $2 / 3$ aux dépens de la proportion des matières azotées et $\mathrm{I} / 3$ aux dépens de la proportion des matières grasses. Elle est très semblable chez les génisses et les vaches mais la proportion de lactose est toujours sensiblement plus élevée chez les génisses. Du $25^{\mathrm{e}}$ au $30^{\mathrm{e}}$ jour, la composition de la matière organique est demeurée pratiquement constante dans les deux groupes avec les valeurs moyennes suivantes:

$\begin{array}{lcc}\text { Lactose Matière organique } \ldots \ldots \ldots \ldots \ldots \ldots & \text { Génisses } & \text { Varhes } \\ \text { Matiéres azotées Matière organique } \ldots \ldots \ldots & 4,3,0 & 42,4 \\ \text { Hatières grasses Matière organique } \ldots \ldots \ldots \ldots & 26,3 & 27,2 \\ \end{array}$

\section{Production des différents constituants.}

I a quantité de lactose augmente très rapidement pendant la prenière semaine, plus lentement ensuite, et atteint son maximum pratiquement en même temps que la quantité de lait (tableau IV) : le $25^{-26}$ e jour, pour l'ensemble des animaux, le $27-28^{\mathrm{e}}$ jour pour les vaches, le 15 -I 6 e jour pour les génisses. En pourcentage de ce maxinum, la production de 
lactose est en général de 40 à $45 \%$ pour les deux premiers jours (moyenne $43,2 \%+2,8$ ), de 60 à $70 \%$ pour le $3-4^{\mathrm{e}}$ jour (moyenne $66,5 \% \pm 3,5$ ). L'influence du niveau de production est particulièrement sensible à la fin de la première semaine : le $7-8$ e jour la production atteint $99 \%$ de son maximum chez les animaux dont la quantité de lait maximum est inférieure à $I 5 \mathrm{~kg}$ mais seulement 80 à $85 \%$ chez les autres.

En moyenne la quantité de matières grasses a augmenté au cours des premiers jours de la lactation, atteint un palier maximum au cours de la deuxième semaine et diminué ensuite de façon sensiblement linéaire. Ėn\% de la production maximum (9-10 ${ }^{\mathrm{e}}$ jour), les valeurs moyennes ont été de $70 \%$ et $88 \%$ le $\mathrm{I}^{\mathrm{er}}-2^{\mathrm{e}}$ et $3-4^{\mathrm{e}}$ jours. La courbe d'évolution des vaches (maximum le $\mathrm{I}_{3}$ - $\mathrm{I}_{4}^{\mathrm{e}}$ jour) a été beaucoup plus aplatie que celle des génisses qui a présenté une pointe maximum le 9-Ioe jour et diminué ensuite plus rapidement $\left(84 \%\right.$ du maximum le $29-30^{\mathrm{e}}$ jour, contre $94 \%$ pour les vaches). On retrouve naturellement la même différence entre les courbes des animaux dont la production de lait maximum est inférieure à $15 \mathrm{~kg}$ de lait (majorité des génisses) et celles dont la production est supérieure. Plus cette quantité de lait est élevée, plus la production maximum de matière grasse est atteinte tard ; il faut noter cependant que le groupe des vaches à production supérieure à $25 \mathrm{~kg}$ a approché sa production maximum de matière grasse dès le $3-4^{\mathrm{e}}$ jour.

En raison de la richesse des laits colostraux, la production de matières azotées a diminué de $25 \%$ entre le $\mathrm{I}^{\mathrm{er}} 2^{\mathrm{e}}$ jour et le $3-4^{\mathrm{e}}$ jour. Elle s'est maintenue à ce niveau jusqu'aux $7-9^{\text {e }}$ jours, puis a diminué de façon sensiblement linéaire. Nous retrouvons cette évolution caractéristique pour tous les groupes d'animaux indépendamment de la quantité de lait, la décroissance étant fonction de celle de la quantité de lait. Cependant, chez les génisses, la production de matières azotées a augmenté entre le $3-4^{\mathrm{e}}$ jour et le $5^{-6 \mathrm{e}}$ jour de $6 \%$ environ.

La production de "caséine " a augmenté au cours de la première semaine chez tous les animaux : en moyenne de $\mathrm{I}_{5} \%$ entre $1 \mathrm{e} \mathrm{I}^{\mathrm{er}}-2^{\mathrm{e}}$ et le $7-8^{e}$ jour. Cette augmentation a été plus accentuée pour les génisses que pour les vaches d'une part, et a été d'autre part en liaison avec le niveau de production. A partir de la $2^{\mathbf{e}}$ semaine la production de caséine a évolué comme la production de matières azotées totales puisque le rapport entre les deux est demeuré constant.

La production de matière organique a augmenté au cours de la première semaine, de $20 \%$ environ, et atteint ou approché son maximum au cours de la deuxième semaine de lactation. Elle s'est maintenue sensiblement constante jusqu'à la fin du mois chez tous les animaux dont la production laitière maximum était supérieure à $15 \mathrm{~kg}$; elle a diminué sensiblement chez les autres et n'a représenté le $29-30^{\mathrm{e}}$ jour que $87 \%$ du maximum atteint le 9 - Io $^{\mathrm{e}}$ jour. 


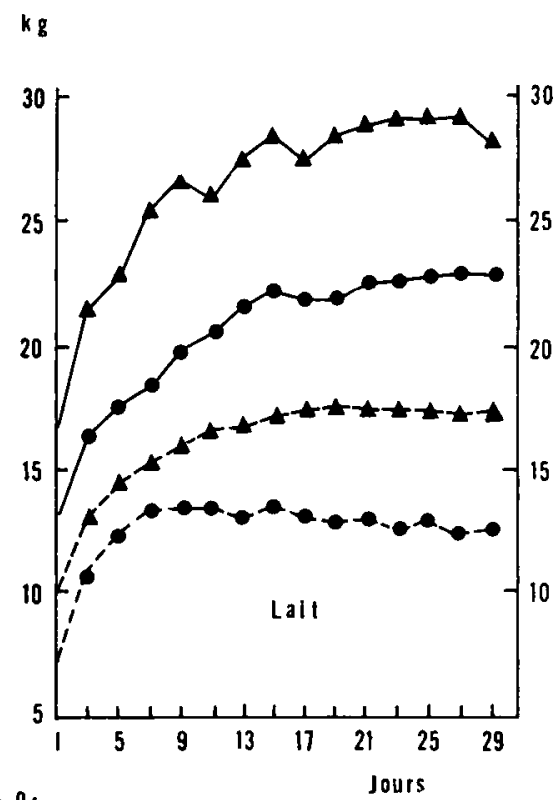

g $\% 0$
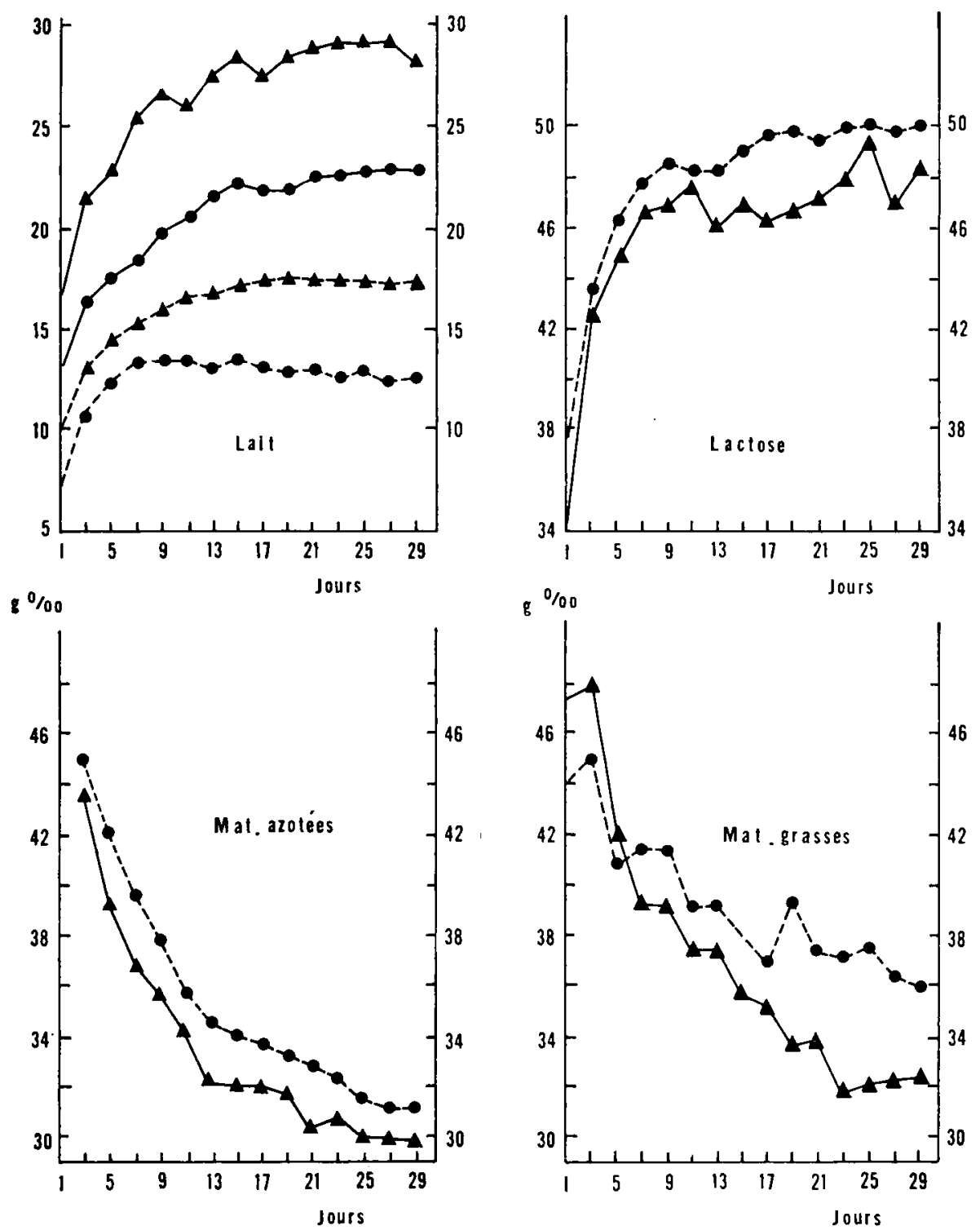

GrapiIique 5. - Influence du niveau de production sur l'évolution de la quantité de lait et des teneurs en lactose, matières grasses et matières azotées sécrétées au cours du premier mois de lactation. 

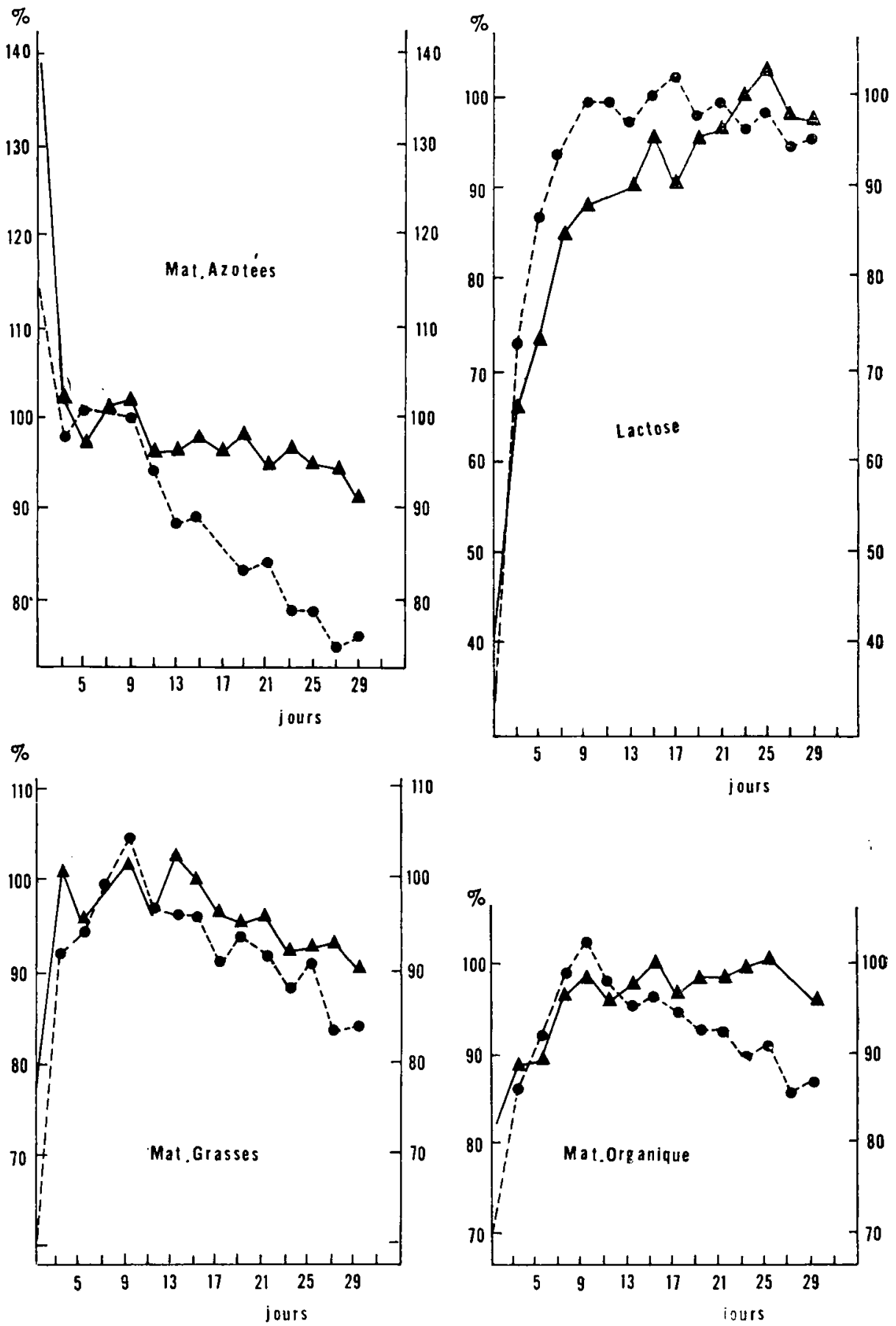

Graphique 6. - Influence du niveau de production sur l'évolution des quantités de lactose, de matières grasses, de matières azotées et de matière organique sér rétées au cours du I er mois de lactation. (Les résultats sont exprimés en p. Ioo de la mộenne hebdomadaire maximum.) 

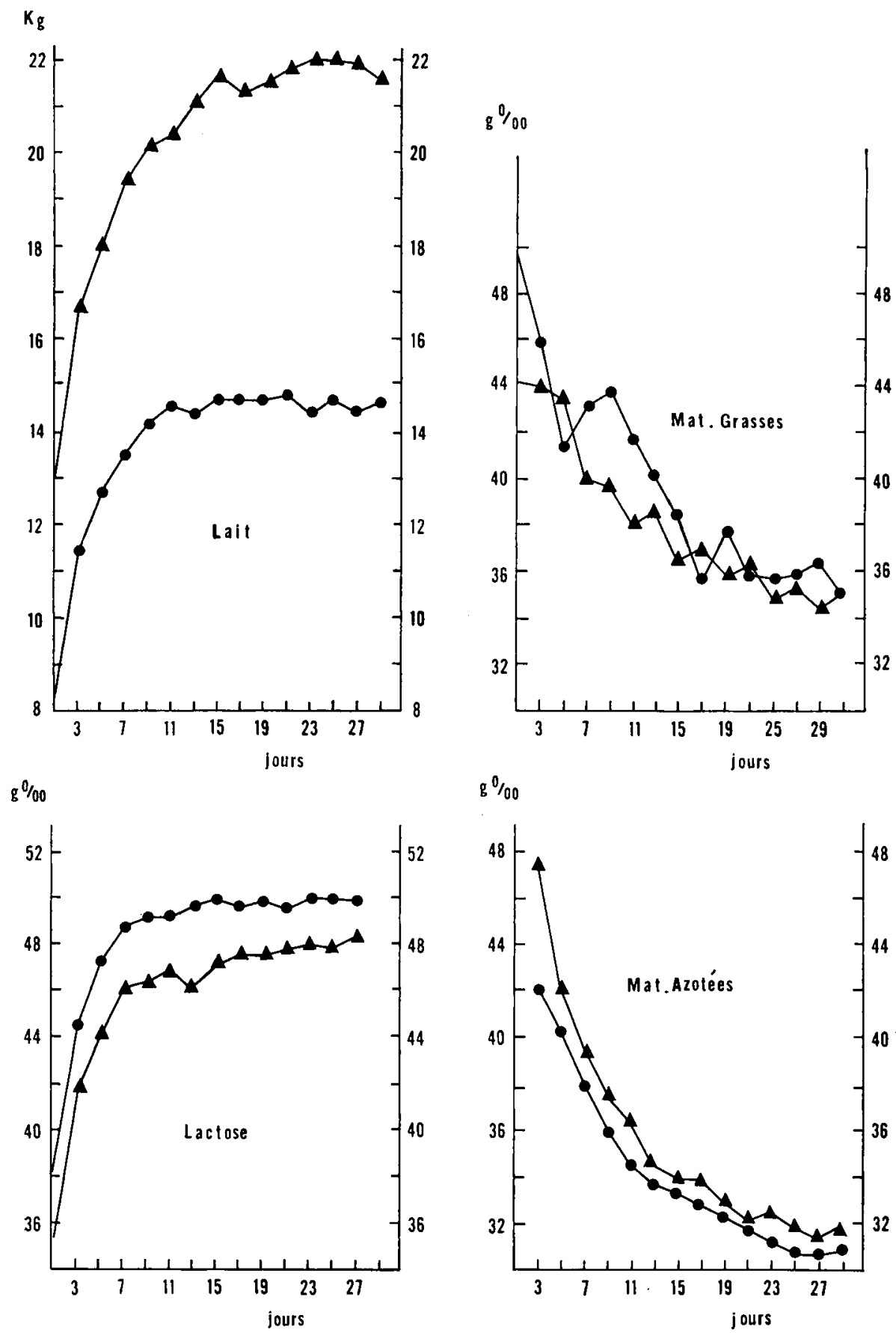

Grapinque 7. - Influence de l'âge sur l'évolution de la quantité de lait et des teneurs en lactose, matières grasses et matières azotées.

- Premières lactations (I6 animaux)

Lactations ultérieures (27 animaux) 

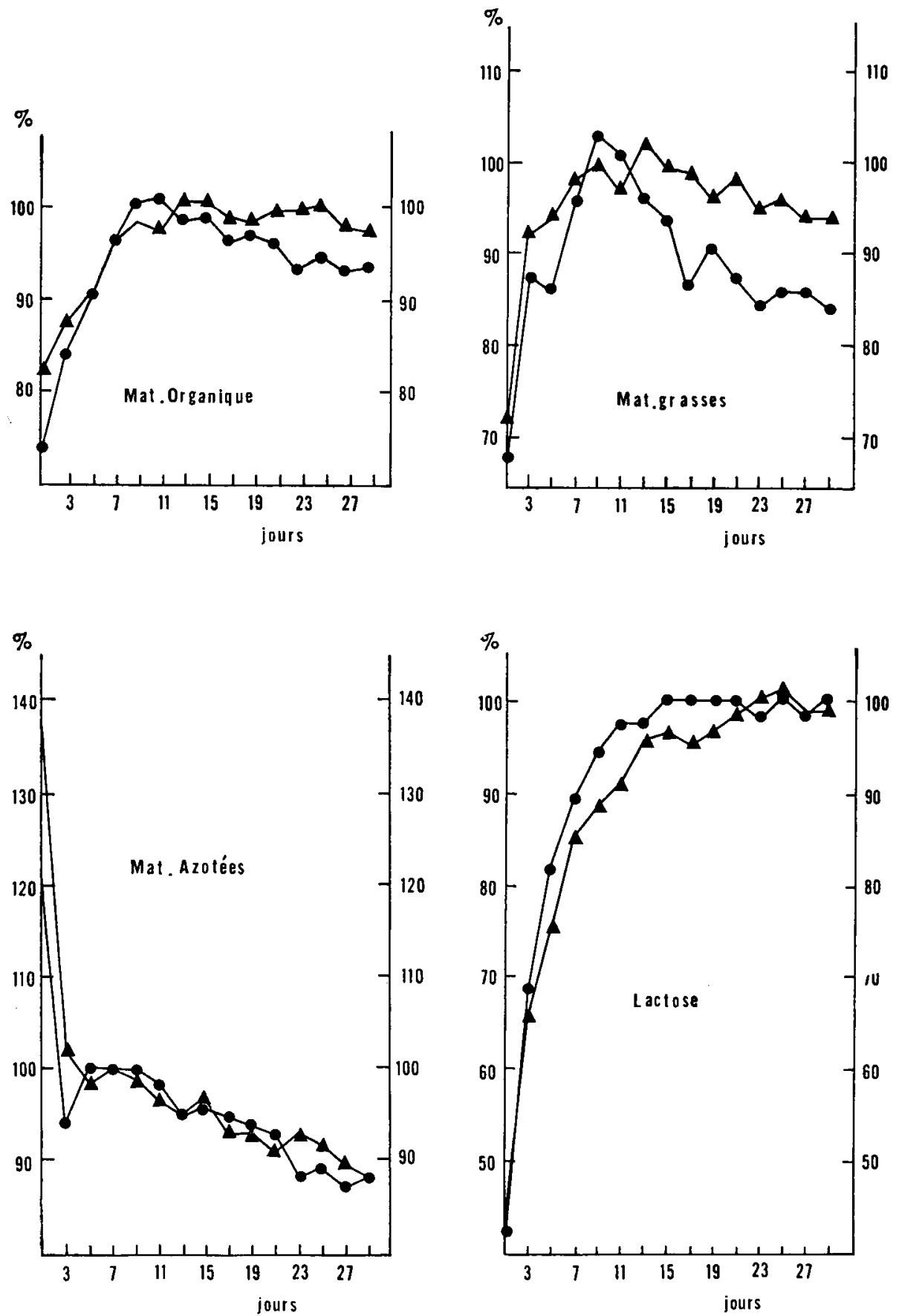

Graphinue 8. - Influence de l'âge sur l'évolution des quantités de lactose, de matières grasses, de matières azotées et de matière organique sécrétées au cours du premier mois de lactation (les résultats sont exprimés en p. Ioo de la moyenne hebdomadaire maximum.)

- Premières lactations (I6 animaux)

- Lactations ultérieures (27 animaux) 


\section{DISCUSSION}

\section{Caractères principaux des premières semaines de la lactation.}

$\left.I^{\circ}\right)$ Pour l'ensemble de nos animaux, le passage du colostrum au lait normal a été très rapide puisqu'il s'est effectué dans la première semaine : les laits du $7-8 \mathrm{e}$ jour ont présenté en effet un rapport caséine/matières azotées pratiquement normal $(76,5 \%)$ et une teneur en lactose très voisine de la moyenne $(46,9 \%)$. L'évolution a été également rapide chez toutes les vaches, indépendamment de leur $n^{\circ}$ de lactation et de leur niveau de production : ainsi la proportion de la caséine dans la matière azotée totale a été de $76,2-76,9-76,8$ et $76,9 \%$ pour les vaches dont la production maximum a été respectivement de moins de $\mathrm{I}_{5} \mathrm{~kg}$, de $\mathrm{r}_{5}$ à $20 \mathrm{~kg}$, de 20 à $25 \mathrm{~kg}$. et de plus de $25 \mathrm{~kg}$. Par contre la composition des laits colostraux a varié de façon considérable d'un individu à l'autre. Il faudrait certes tenir compte d'autres critères pour fixer les limites exactes de la, phase colostrale (Cf. Houdinière I944); elle semble cependant sensiblement plus courte qu'on ne l'admet généralement.

$\left.2^{\circ}\right)$ Il en est de même pour la durée de la phase ascendante de la lactation : toutes les vaches ont atteint leur production laitière maximum avant la fin du premier mois (tableau I), en moyenne d'autant plus tôt que leur production était plus faible (graphique 5). On peut dire schématiquement que, trois semaines après le vêlage, toutes nos vaches donnaient une quantité de lait maximum, d'environ $70 \%$ plus élevée que la production initiale des deux premiers jours. Par rapport à celle-ci, la sécrétion de lactose a augmenté dans des proportions beancoup plus importantes jusqu'à 225 à $230 \%$ à la fin du premier mois. Par contre, les sécrétions de matières grasses et de caséine ont atteint, dès la deuxième semaine, des maximum beaucoup moins accentués qui ont été respectivement de $\mathrm{r}_{40} \%$ et $120 \%$ de la production initiale (graphique 4 ). Il s'agit là d'un fait très important que nous avions déjà signalé à l'aide d'analyses hebdomadaires (JARRIGE et ROSSE'TTI I947). I,ARSON et KENDALL (I957) 1'ont précisé dans le cas des protéines et ont constaté, sur huit vaches, que les sécrétions de matières azotées totales (en dehors des laits colostraux), $\alpha$ caséine, $\beta$ caséine, $\alpha$ lactalbumine et $\beta$ lactoglobuline passaient par un maximum 5 jours après le vêlage.

Il faut souligner que nos vaches ont été correctement alimentées, non seulement après le vêlage mais aussi penđant la période de repos au cours de laquelle elles ont reçu une alimentation abondante comportant, 1'hiver, une certaine quantité d'aliments concentrés, pour les « mettre en état ». Il est possible que la production des vaches insuffisamment alimentées avant le vêlage, augmente plus lentement et n'atteigne son maximum que plus tard, surtout chez les fortes productrices. 
$\left.3^{\circ}\right)$ La composition du lait présente au cours des premières semaines de lactation une évolution rapide et régulière, semblable chez tous les animaux, indépendamment de leur âge et de leur niveau de production. La teneur en lactose augmente suivant une loi hyperbolique, tout comme la quantité de lait; la teneur en matières azotées diminue suivant une droite en coordonnées logarithmiques ou, mieux, suivant deux droites se recoupant le I3-I4 ${ }^{\mathrm{e}}$ jour (qui ont pent-être une signification physiologique particulière). Le fait que nous ayons pu obtenir des expressions mathématiques satisfaisantes malgré le nombre assez limité d'animaux dont les productions étaient très différentes, montre que cette évolution de la composition du lait est un caractère physiologique fondamental de 1'activité de la mamelle au début de la lactation.

L'évolution semble plus rapide chez les vaches en première lactation, 1lotamment pour les teneurs en lactose et en matières grasses qui sont d'ailleurs systématiquement plus élevées qu'aux lactations ultérieures.

\section{Conséquences nutritionnelles.}

Il ressort du tableau $V$ établi pour l'ensemble de nos 43 animaux que la valeur calorifique de la production laitière a été très élevée dès les deux preniers jours et a atteint son maximum au milieu de la deuxième semaine de lactation. Ainsi, les besoins énergétiques de ces animaux ont approximativement doublé immédiatement après le vêlage (on peut estimer à 6 u.f. les besoins en énergie nette des vaches de 550 à $600 \mathrm{~kg}$ dans le dernier mois de gestation) et n'ont augmenté ensuite que de $20 \%$ au cours des ro jours suivants.

Quant aux besoins azotés, ils ont été pratiquement maximum dès les premiers jours, même si nous ne tenons compte que des protéines synthétisées à partir du vêlage en éliminant celles accumulées avant (inmunoglobulines). Ils se sont élevés à environ I ooo g de matières azotées digestibles par jour en admettant que celles-ci sont utilisées dans la proportion de $65 \%$ (cf. JARRIGE et RossETI I957); ils ont donc été près de trois fois plus élevés que dans le dernier mois de gestation (environ $370 \mathrm{~g}$ pour des vaches de $600 \mathrm{~kg}$.)

I,e " démarrage " de la lactation entraîne donc une augmentation considérable et soudaine des besoins énergétiques et azotés (et minéraux) beancoup plus rapide qu'on ne le pense généralement. Malheureusement 1'appétit de la vache n'augmente que très lentement contrairement à celui de la rate (BRTCE I957), de io à $20 \%$ entre la dernière semaine de gestation et la première semaine de lactation et de $20 \%$ ensuite jusqu'à la fln du deuxième mois de lactation (JOURNET et JARRIGE; résultats non publiés). Les évolutions différentes des besoins et de l'appétit sont sousestimées voire ignorées par de nombreux éleveurs; beaucoup de vaches sont ainsi sous-alimentées au cours des premières semaines, ce qui diminue 


\section{TABLEAU V}

Evolution de la valeur calorifique du $\mathrm{kg}$ de lait, de la production laitière et des besoins énergétiques de production (moyenne des 43 animaux).

(Coefficients : 9,25-5,65 et 3,9 cal. par g. de matières grasses, de matières azotées et de lactose - Besoin de o,4 u. f. pour 750 Cal, de lait).

\begin{tabular}{c|c|c|c}
\hline \hline Jour & $\begin{array}{c}\text { Valeur calorifique } \\
\text { du kg de lait } \\
\text { Cal. }\end{array}$ & $\begin{array}{c}\text { Valeur calorifique } \\
\text { de la production laitière } \\
\text { Cal. }\end{array}$ & $\begin{array}{c}\text { Besoin énergétique } \\
\text { de production } \\
\text { u. f. }\end{array}$ \\
\hline $1-2$ & I o10 & Ir 320 & 6,0 \\
$3-4$ & 841 & 12282 & 6,5 \\
$5-6$ & 792 & 12679 & 6,8 \\
$7-8$ & 781 & 13440 & 7,2 \\
$9-10$ & 771 & 13806 & 7,4 \\
$11-12$ & 750 & 13645 & 7,3 \\
$13-14$ & 739 & 13751 & 7,3 \\
$15-16$ & 720 & 13750 & 7,3 \\
$17-18$ & 711 & 13444 & 7,2 \\
$19-20$ & 706 & 13409 & 7,2 \\
$21-22$ & 701 & 13455 & 7,1 \\
$23-24$ & 691 & 13258 & 7,1 \\
$25-26$ & 692 & 13349 & 7,0 \\
$27-28$ & 685 & 13090 & 7,0 \\
$29-30$ & 685 & 13022 & \\
\hline
\end{tabular}

non seulement la quantité de lait produite pendant cette période, mais encore celle produite dans la suite de la lactation (FLUX et PATCHEL, I955 - Patches I957). Cette sous-alimentation risque naturellement d'être d'autant plus fréquente et plus sévère que les vaches ont une production plus élevée.

\section{Aspects métaboliques.}

Nos résultats permettent de poser un certain nombre de problèmes sur les mécanismes de la sécrétion du lait.

I $^{\mathrm{o}}$ Le premier problème est commun à toutes les variations de la production laitière, à savoir : comment expliquer l'augmentation des sécrétions de lactose, de matières grasses et de caséine au cours des premiers jours de la lactation? On peut envisager schématiquement deux mécanismes principaux : une augmentation du nombre de cellules sécrétrices d'une part, une augmentation de l'activité synthátique des cellules d'autre part.

Le premier aspect à été étudié chez les animaux de laboratoire par les techniques histologiques et, plus récemment, par la quantité d'acide désoxyribonucléique (D. N. A.) de la mamelle (par unité de poids). Cette quantité est en effet proportionnelle au nombre de noyaux puisqu'on admet que la teneur en D. N. A. de chaque type de cellule somatique est 
constante. Chez la rate GREENBAUM et SIATER (r957) constatent ainsi que la teneur en D. N. A. de la mamelle augmente considérablement entre le jour de la mise-bas et le $3^{\mathrm{e}}$ jour de la lactation et demeure ensuite remarquablement constante ; ils supposent donc qu'il y a une "vague de mitoses " alux environs de la parturition. SMI'TH et RICHTERICH (I958) ont eux aussi observé une augmentation du D. N. A. après la mise-bas (toujours chez la rate) jusqu'à un maximum situé au Io jour de lactation ; ils l'attribuent également à des divisions cellulaires dont ils ont observé quelques cas. Les résultats sur le cobaye sont plus contradictoires : tandis que Smith (I956) n'observe aucune variation du D. N. A. au cours de la lactation, NAito trouve un maximum le jour de la mise-bas (I958 a) en même temps qu'un nombre maximum de cellules par champ microscopique $($ r958 b).

Ces travaux sont cependant d'un intérêt assez limité pour nous expliquer les variations observées chez la vache pour trois raisons principales : d'abord ils portent sur des espèces très différentes ; ensuite les méthodes utilisées pour le dosage des acides nucléiques sont assez rudimentaires; enfin la constance de la teneur en D. N. A. des cellules mammaires a été infirmée par GRIFFITH et TURNER (I957) mais confirmée par NAITO (I958).

Toujours chez les animaux de laboratoire, 1'activité métabolique des cellules mammaires augmente au début de la lactation. Par rapport à la fin de la gestation, la consommation d'oxygène in vitro est multipliée par trois chez la rate le 8 e jour (FOLLEY et FRENCH I949) et par quatre chez

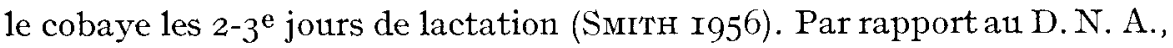
la quantité d'acide ribonucléique augmente chez la rate après la mise-bas (Kirkham et Turner I955 - Grafinbaum et Slater I957 - SMith et RICHTERICH I958) de même que certaines activités enzymatiques : succinoxydase, cytochrome oxydase (SMITH et RICHTERICH I958).

$2^{\circ}$ Le deuxième problème est soulevé par 1'évolution de la composition de la " matière organique " qui est la somme: matières grasses + matières azotées + lactose. Nous pouvons admettre schématiquement que cette somme représente au mieux le produit synthétisé par les cellules séerétrices, produit ensuite dilué dans une certaine quantité d'eau. A 1'appui de ce schéma on peut citer le fait qu'à la fin du premier mois, la composition de cette somme semble beaucoup moins variable d'un animal à l'autre que la composition du lait.

S'il en est ainsi, les cellules modifient progressivement leur activité au début de la lactation : elles sécrètent relativement plus de lactose et moins de protéines et de lipides, d'ailleurs probablement à partir des mêmes précurseurs sanguins. Au contraire dans la deuxième moitiẻ de la lactation elles sécrètent relativement moins de lactose et plus de protéines et de lipides (JARRIGE I956 - JARRIGE et ROSSETTI I957). Quelles sont donc les causes (hormones) et les mécanismes (enzymes) de ces modi- 
fications de 1'activité des cellules ? Tel est le deuxième problème, d'ailleurs très général.

$3^{\circ}$ Enfin, dernière question : pourquoi la sécrétion d'eau continuet-elle à augmenter au-delà de la deuxième semaine delactation, alors que les sécrétions de protéines et de lipides commencent à diminuer? On pourrait admettre qu'elle augmente avec la sécrétion de lactose selon l'hypothèse de TAylor et Husband (I923) et de Brody (I945).

A la limite, tout se passerait comme si 1'équilibre hormonal contrôlait directement la synthèse du lactose dans les cellules sécrétrices : cette dernière déterminerait la quantité d'eau exportée et, par là, la quantité de lait en même temps que la dilution des lipides et des protéines. I1 s'agit là d'un schéma hypothétique et simpliste dont le principal intérêt est de fournir provisoirement une explication commode des variations de la composition du lait au cours de la lactation. Notons à ce propos que chez le cobaye, la quantité de lactose synthétisée in vitro par unité de D. N. A. est maximum les $2-3^{\mathrm{e}}$ jours de la lactation, soit en même temps que la quantité de lait produite.

\section{SUMMARY}

I. Changes in the secretion of fat, total proteins $(\mathrm{N} \times 6,38)$, casein and lactose were studied on the milk of 43 cows during the first month of lactation. Milk samples were taken from the milk of each cow at each milking; samples of two consecutive days were mixed in proportion to yield, so that $I_{5}$ mixed samples were analysed for each cow.

2. The daily milk yield and the lactose content showed a hyperbolic increase (graph. I). The daily production of total proteins showed a logarithmic decrease (graph. 2) and the fat content decreased in a less regular manner (grapli. 2).

3. The dates after calving when maximum daily production was reached were as follows (graph. 4):

a) the Ist and 2nd days for total proteins;

b) the $9^{\text {th }}$ and roth days for casein ( $20 \mathrm{p}$. Ioo of the initial values obtained on the first two days).;

c) the gth and roth days for fat (I42 p. IOO);

d) the $9^{\text {th }}$ and Ioth days for the calorific value (r22 p. 10o) ;

e) the 25 th and 26 th days for milk (I 72 p. IOO) ;

f) the $25^{\text {th }}$ and 26 th days for lactose (230 p. I0o).

4. The composition of the organic matter (ie. the sum : butterfat + total proteins + lactose) showed a regular evolution. The proportion of lactose increased while there was a correspondant decrease in the proportion of proteins and fat (graph. 3).

5. On the average, the protein requirements of the cows were at their maximum immediately after calving and the maximum energy requirements occured during the second week. 


\section{RÊFÉRENCES BIBLIOGRAPHIQUES}

Brody S., I945. Bioenergetics and growth, Reinhold.

BRUCE H. M., 1957. Lactation and food intake in the rat. $4^{c}$ Congrès International de Nutrition, Paris. Résumé des communications, p. I9.

Delage J., Leroy A. M. et Poly J., I953. Une étude sur les courbes de lactation. Ann. Zooetch., 2, 225.

FOLLEY J. S., et FRENCH T. H., I949. The intermediary metabolism of the mammary gland. 2. Respiration and acid production of mammary tissues during pregnancy, lactation and involution in the rat. Biochem. J., 45, 27 .

Greenbaum A. L. et Si.ater 'I'. F., I957. Changes in the levels of the nucleic acids of the mammary glands of rats during pregnancy, lactation and mammary involution. Biochem. $J ., 66,155$.

Griffith D. R. et Turner C. W., I957. Desoxyribonucleic Acid (DNA) content of mammary gland during pregnancy and lactation. Proc. Soc. Exp. Biol. Med., 95, 347.

Houdriù:Re A., I944. Le colostrum de vache. Composition. Propriétés. Répetcussions en industrie laitière. Le Lait, 24, Io8.

JARRIGE R., I956. Variations de la teneur en matières azotées des laits individuels. $V^{2} I^{\mathrm{e}}$ Congr. Internat. de Zootech., Madrid, 5.

JARRIGE R. et Rosse'TTI C., I957. Étude sur les variations de la richesse en constituants azotés des laits de vache. Ann. Zootech., 6, 4I.

Kirkham W. R. et Turver C. W., I953. Nucleic acids of the mammary glands of rats. Proc. Soc. Exp. Biol. Med., 83, I23.

LaRson B. L. et KeNDali, K. A., I957. Protein production in the bovine daily production of the specific milk proteins during the lactation period. J. Dairy Sci., 40, 377.

NAI'TO M., I958 a. Oxygen consumption and lactose synthesis rates of mammary gland slices from lactating Guinea Pigs. J. Dairy Res., 25, I7.

NAI'TO M., I958 b. Histological changes in the mammary gland of Guinea Pigs during lactation. J. Dairy Res., 25, 392.

Parrish D. B., Wise G. H., Hughes J. S. et Atkeson F. W., 1950. Properties of the colostrum of the dairy cow. V. Yield, specific gravity and concentrations of total solids and its various components of colostrum and early milk. J. Dairy Sci., 33, 457.

Rowland S. J., I938. The protein distribution in normal and abnormal milk. J. Dairy Res., 9, 47.

Somogyi M., I 952 . Notes on sugar determination. J. Biol. Chem., 195, I9.

Smith C. C., I956. The respiration and composition of the mammary gland of the Guinea Pig during pregnancy and lactation. Arch. Biochem. Biophys., 60, 485 .

SMith 'T. C. et Richterich B., I958. Patterns of succinoxidase, cytochrome oxidase, nucleic acids and other constituents in mammary glands of pregnant and lactating rats. Arch. Biochem. Biophys., 74, $39 \%$.

TAYioR W. et Husiaxd A. D., I922, The effect on the percentage composition of milk of :

a) variations in the daily volume, and

b) variations in the nature of diet. S. Agric. Sci., 12,

Turner C. W., Ragsdale A. C. et Brody S., I923, How the advance of the period of lactation affects the milk flow, J. Dairy Sci., 6, 527 . 